Ambient Science, 2020: Vol. 07(Sp1); 07-13

DOI:10.21276/ambi.2020.07.sp1.oa01

\title{
Determination of Active Life Constraints in Adults
}

\section{Sebnem Sarvan Cengiz}

Department of Sport Sciences, Manisa Celal Bayar University, Manisa, Turkey

Study Area: Manisa, Turkey

Coordinates: $38^{\circ} 37^{\prime} 50^{\prime \prime} \mathrm{N} 27^{\circ} 25^{\prime} 20^{\prime \prime} \mathrm{E}$

Key words: Social Effect; Lack of Energy; Lack of Wıll; Fear of Injury; Lack of Skıll; Access of resources

\section{Abstract}

The "Active Life Constraints Scale" (ALCS) (Heath, 2009) total 5010 participants selected by simple random sampling method. In the original version, there are 21 items and 7 subscales, and it is in four-point likert type; however, in the Turkish adaptation, it is seen after confirmatory factor analysis that the scale has 7 subscales and 20 items. As a result of the confirmatory factor analysis conducted to test the reliability of the scale, the cronbach alpha value of the 20-item scale was found 0.819 . For the subscales, the reliability scores were found as follows: lack of time 0.981 , social effect 0.921, lack of energy 0.854, lack of will 0.773 , fear of injury 0.862 , lack of skill 0.875 and lack of resources o.816. Independent variables were evaluated using MANOVA analysis which revealed that the main effect of the variable "age" is signif icant in all subscales of ALCS, the main effect of the variable "gender" is significant in "social effect", "lack of will" and "lack of skill" subscales, the main effect of the variable "body mass index" is signif icant only in "lack of energy" subscale. It is determined that $45-54$ years of age group has the highest scores from the subscales "lack of time", "lack of energy" and "lack of will" of ALCS in terms of age variable. When gender variable is considered, it is determined that both women and men have high scores from "lack of energy" subscale. When body mass index variable is considered, overweight participants have the high scores from "lack of energy" subscale. Finally, it could be suggested that the most important factors that constrain adults from an active life are "lack of energy", "lack of time" and "lack of will"

fitness; consequently, aging aggravatedly causes a lesser amount of physical activity and a greater amount of decreased physical fitness cycle (Meijer et al., 1999). Physical activity is defined as the body movements produced by skeletal muscles resulting in burning off calories. Since burning calories is related to energy consumption, it helps decrease the body weight, and thank to that, illnesses such as obesity, diabetes and coronary artery diseases can be prevented (Erbs et al., 2010).

Although none of the physical activity types can stop the biological aging process, there are evidences showing that regular exercise can minimize the physiological effects of a sedentary life style, and limit the development and improvement of chronic diseases and injuries; and increase the active life expectancy. Furthermore, there are studies 
revealing the psychological and cognitive benefits of regular exercise participation for elderly population in the literature (Chodzko-Zajko et al., 2009).

In the study conducted by Lear et al. (2016), the results obtained from the individuals who constitute both the wealthy and poor parts of the society, being physically active both expand the life-span and decreases the risk of disease. Kara et al. (2018) also concluded in their study that participation in regular physical activities has a significant effect on their existing potential to use social communication. The American College of Sports Medicine and American Heart Association suggest that scientific evidences show a regular and intermediate level physical activity provide with significant benefits for health. In the light of results, National Physical Activity Committee developed a guideline, and recommended that each American adult should do intermediate level physical activity at least 150 minutes or more every week (Fleg et al., 2005).

According to Turkish Nutrition and Health Research, while the rate of the ones who have never done exercise before is respectively $41.4 \%$ and $44.6 \%$ for $12-14$ years of age and 15-18 years of age males, it is determined that this rate increases respectively to $69.5 \%$ for $19-30$ years of age, $73.2 \%$ for $31-50$ years of age and $83.7 \%$ for $75+$ years of age. In terms of females, the rate of the ones who have never done exercise increases with age, and it is observed that the rate is $69,8 \%$ for $12-14$ years of age, $72.5 \%$ for $5-18$ years of age, $76.6 \%$ for $19-30$ years of age and $88.0 \%$ for 75 +years of age. According to Risk Factors for Chronic Diseases Research, $87 \%$ of women and $77 \%$ of men across the country do not do physical activity sufficiently. In another study with $65^{+}$ individual; on the other hand, it is determined that only $30 \%$ of the participants go walking (Demirel et al., 2014).

When the literature is reviewed, it is understood that sedentary lifestyle is a public health problem due to its adverse effects on health (DiSantis et al., 2013; Schembre et al., 2015; Spartano et al., 2019). The obtained actual data show that $23 \%$ of the adults across the world do not meet the global physical activity recommendations. Therefore, physical inactivity is defined as the biggest public health problem and a pandemic of 21st century (Koz, 2018). Inactive lifestyle is on the top of the problems for a modern community that does their daily shopping online on their personal computer or smart phones.

Although technological improvements make life easier in a sense, in the long term the number of inactive individuals increase and this affects health adversely. Physical inactivity which is one of the common risk factors of chronic diseases appears in the fourth rank (6\% of the deaths in the entire world) in the raking for the risk factors causing death (Demirel et al., 2014). Although the benef its of doing physical activity on a regular basis is well known, it is determined in a study conducted in 15 European country that participation in regular physical activity which is recommended is less than 50\% (Rütten \& Abu-Omar, 2004). In order to gain the benef its from physical activities, being active should become a part of daily routine. Physical activities, which are regular, in a designated duration and frequency and continues throughout the life, improves and enhances both individual and public health. It is reported that individuals who lead an inactive lifestyle should start physical activities for short durations and should improve gradually (Chou et al., 2012). Several physical and environmental factors may restrain individuals from participating in physical activities (Paterson et al., 2007).

Families and friends may behave as good or bad models, or they can accompany individuals during physical activity. Especially physical environment can pose an obstacle for individuals in physical activity participation or during physical activity. Environment where people live can be deprived of transportation to the areas to do physical activity (Peeters \& Mets, 1996). A successful aging process can be affected by several factors which are caused by physical, functional, psychological and social health as a multiple and multicausal situation (Phelan et al, 2004). It is reported that regular physical activity has a positive effect on one of the quality of life areas in adults (Rejeski et al., 2002). The results of the research on this issue reveals that attending to physical activities such as recreational activities in leisure have some benefits; however, it is also determined that attending to only special exercises will lead to better physical functions (Penedo \& Dahn, 2005; Lubans et al., 2016).

It is known that physical activity can prevent premature death, cardiovascular diseases and some cancer types. The half of the all physical regression that combines with aging can be prevented if the physical activity can be maintained in a desired level (Camarri et al., 2006). Despite the increasing evidences about benef its of the exercise, the rate of people who do regular exercise in their 65 or later years is less than $40 \%$, and the majority of elderly population is too sedentary to obtain these benefits (Watson et al., 2016).

It can be seen that physical activity plays an important role among the factors that affect the mobility and quality of life of the elderly population. Unfortunately, the studies testing the potential benefits of physical activity and its relationship with quality of life, and multivariate problems related to proceeding of aging in different terms are scarce in number. In the light of the actual studies in the literature, it is revealed that adults lead an inactive life in general. The aim of this study is to determine the constraints related to living an active life in terms of adult population.

\section{Materials and Methods:}

In the current study, scanning method which determines the opinions or features such as skills, interests, or attitudes of a study group (Büyüköztrük etal., 2017) was used. A total 
of 721 individuals residing in Manisa and Izmir who were selected by simple random sampling method participated for the confirmatory factor analysis for the scale; on the other hand-, for the scanning model application, 2588 females (57\%) and 2155 males (43\%) in total 5010 individuals whose age range is between $45\left(\mathrm{n} \_3336.6 \%\right)$ and $86(\mathrm{n}=130.3 \%)$ voluntarily participated.

Data Collection: in the study, "Constraints Related to Being Active Questionnaire" developed by Heath (2009) and translated into Turkish language by Isintas Arik (2018) was used as a data collection tool. The measuring tool was evaluated in terms of language comprehensibility by a pilot study on 30 participants, and as a result, the title of the scale was decided as "Active Life Constraints Scale". The original scale which has 21 items and 7 subscales, formed with o-3 points in four-point likert type was brought into use of Turkish samples. In the study, it was seen that the scale consisted of 20 items and 7 subscales (15th item was excluded) as a result of the confirmatory factor analysis. Since the corrected item-total correlation (-0.369) was affected negatively in reliability analysis, when 15th item was excluded, the reliability increased. The scale was given to the participants by hand. Voluntary participation principle was also considered. In the instructions, detailed information about how to fill in the form was given. In the current study, Constraints Related to Being Active Questionnaire has been used for the first time on adults; therefore, reliability analysis (Cronbach Alpha), content validity (27\% low-high group analysis) and Confirmatory Factor Analysis (CFA) were conducted. Exploratory Factor Analysis (EFA) had been developed by Cengiz et.al. before, and the subscales had been determined, the translation had been completed and applied on a young sample; therefore, EFA was not conducted. Only Cronbach Alpha, item analysis and CFA were conducted to determine the reliability and validity for $45^{+}$adults. The analysis showing that the use of the scale on Turkish adult samples between $45-86$ is convenient is presented below.

Table*1: Subscale and Overall Scale Reliability Analysis of Constraints Related to Being Active Questionnaire

\begin{tabular}{lllllllll}
\hline $\mathrm{n}=721$ & $\mathrm{a}$ & $\mathrm{b}$ & $\mathrm{c}$ & $\mathrm{d}$ & $\mathrm{e}$ & $\mathrm{f}$ & $\mathrm{g}$ & $\mathrm{h}$ \\
\hline$\alpha$ & .981 & .921 & .854 & .773 & .862 & .875 & .816 & .760 \\
Number & 2 & 3 & 3 & 3 & 3 & 3 & 3 & 20 \\
\hline
\end{tabular}

a-LackofTime;b-SocialEffect; c-LackofEnergy; d-LackofWill; e-FearofInjury;f-LackofSkill;g-AccesstoResources; h-TotalItem

In table-1, the Cronbach Alpha reliability analysis for CRBAQ is presented. As a result of the reliability analysis, it can be seen that each subscale and overall items are $\alpha>0.70$. As per the result, it is determined that CRBAQ is a reliable measurement tool for the Turkish adults between 45-86.

In table 2, the comparison of low-high score groups of $27 \%$ for Constraints Related to Being Active Questionnaire is presented. When the $27 \%$ low and $27 \%$ high item means

which are formed according to the overall item scores of the scale are examined, the $27 \%$ low score mean $(1.72 \pm 1.047)$ of $15^{\text {th }}$ item was found higher than $27 \%$ high score mean $(.80 \pm .709)$. When the remaining 20 items' $27 \%$ low score and $27 \%$ high score differences were compared, a significant difference was determined. Hereunder, the remaining 20 items show distinctiveness between the $27 \%$ low score and $27 \%$ high scores.

Table 2: Comparison of L-H Score Groups (Low / High) of 27\% for Constraints Related to Being Active Questionnaire

\begin{tabular}{|c|c|c|c|c|c|c|c|}
\hline Sport & & $\mathrm{n}$ & $\mathrm{x}$ & $\mathrm{s}$ & sd & $\mathrm{t}$ & $\mathrm{p}$ \\
\hline \multirow[t]{2}{*}{ Item 1} & L \%27 & 1352 & 1.36 & 1.004 & 2324.633 & -35.797 & .000 \\
\hline & H \%27 & 1352 & 2.53 & .655 & & & \\
\hline \multirow[t]{2}{*}{ Item 2} & L \%27 & 1352 & 1.1598 & .98000 & 2388.751 & -37.514 & .000 \\
\hline & H \%27 & 1352 & 2.3713 & .67063 & & & \\
\hline \multirow[t]{2}{*}{ Item 3} & L \%27 & 1351 & 1.6188 & .98533 & 2358.413 & -25.777 & .000 \\
\hline & H \%27 & 1352 & 2.4504 & .66010 & & & \\
\hline \multirow[t]{2}{*}{ Item 4} & L \%27 & 1352 & 1.5688 & 1.02724 & 2423.922 & -24.780 & .000 \\
\hline & H \%27 & 1352 & 2.4149 & .72198 & & & \\
\hline \multirow[t]{2}{*}{ Item 5} & L \%27 & 1352 & 1.5348 & 1.00641 & 2534.292 & -26.096 & .000 \\
\hline & H \%27 & 1352 & 2.4357 & .77355 & & & \\
\hline \multirow[t]{2}{*}{ Item 6} & L \%27 & 1352 & 1.2515 & 1.01305 & 2462.830 & -30.915 & .000 \\
\hline & H \%27 & 1352 & 2.3033 & .73390 & & & \\
\hline \multirow[t]{2}{*}{ Item 7} & L \%27 & 1352 & 1.2204 & 1.00933 & 2536.930 & -32.018 & .000 \\
\hline & H \%27 & 1352 & 2.3299 & .77759 & & & \\
\hline \multirow[t]{2}{*}{ Item 8} & L \%27 & 1352 & 1.3720 & .99884 & 2329.215 & -35.288 & .000 \\
\hline & H \%27 & 1352 & 2.5178 & .65385 & & & \\
\hline \multirow[t]{2}{*}{ Item 9} & $\mathrm{~L} \% 27$ & 1352 & 1.0318 & 1.03943 & 2375.529 & -37.842 & .000 \\
\hline & H \%27 & 1352 & 2.3240 & .70428 & & & \\
\hline \multirow[t]{2}{*}{ Item 10} & L \%27 & 1352 & 1.5377 & 1.01655 & 2241.170 & -28.212 & .000 \\
\hline & H \%27 & 1352 & 2.4527 & .62336 & & & \\
\hline \multirow[t]{2}{*}{ Item 11} & $\mathrm{~L} \% 27$ & 1352 & 1.5244 & .99339 & $2457 \cdot 366$ & -23.270 & .000 \\
\hline & H \%27 & 1352 & 2.2996 & .71656 & & & \\
\hline \multirow[t]{2}{*}{ Item 12} & L \%27 & 1352 & 1.3698 & .99484 & 2507.566 & -25.070 & .000 \\
\hline & H \%27 & 1352 & 2.2182 & .74738 & & & \\
\hline \multirow[t]{2}{*}{ Item 13} & L \%27 & 1352 & 1.2152 & .99233 & 2502.917 & -32.826 & .000 \\
\hline & H \%27 & 1352 & 2.3217 & .74261 & & & \\
\hline \multirow[t]{2}{*}{ Item 14} & L \%27 & 1352 & 1.2049 & 1.02459 & 2528.453 & -29.540 & .000 \\
\hline & H \%27 & 1352 & 2.2411 & .78352 & & & \\
\hline \multirow[t]{2}{*}{ Item 15} & L \%27 & 1352 & 1.7241 & 1.04739 & 2375.266 & 26.571 & .000 \\
\hline & H \%27 & 1352 & .8099 & .70953 & & & \\
\hline \multirow[t]{2}{*}{ Item 16} & L \%27 & 1352 & 1.1893 & .97925 & 2350.640 & -37.694 & .000 \\
\hline & H \%27 & 1352 & 2.3950 & .65130 & & & \\
\hline \multirow[t]{2}{*}{ Item 17} & L \%27 & 1352 & 1.5584 & .99346 & $2257 \cdot 726$ & -30.840 & .000 \\
\hline & H \%27 & 1352 & 2.5392 & .61677 & & & \\
\hline \multirow[t]{2}{*}{ Item 18} & $\mathrm{~L} \% 27$ & 1352 & 1.5666 & .97489 & 2522.016 & -23.449 & .000 \\
\hline & H \%27 & 1352 & 2.3476 & .74140 & & & \\
\hline \multirow[t]{2}{*}{ Item 19} & L \%27 & 1352 & 1.4379 & .97670 & 2518.472 & -25.916 & .000 \\
\hline & H \%27 & 1352 & 2.3018 & .74053 & & & \\
\hline \multirow[t]{2}{*}{ Item 20} & $\mathrm{~L} \% 27$ & 1352 & 1.2382 & .98595 & 2529.009 & -31.722 & .000 \\
\hline & H \%27 & 1352 & 2.3092 & .75434 & & & \\
\hline \multirow[t]{2}{*}{ Item 21} & L \%27 & 1351 & 1.2413 & 1.00271 & 2575.484 & -28.269 & .000 \\
\hline & H \%27 & 1352 & 2.2286 & .80173 & & & \\
\hline
\end{tabular}

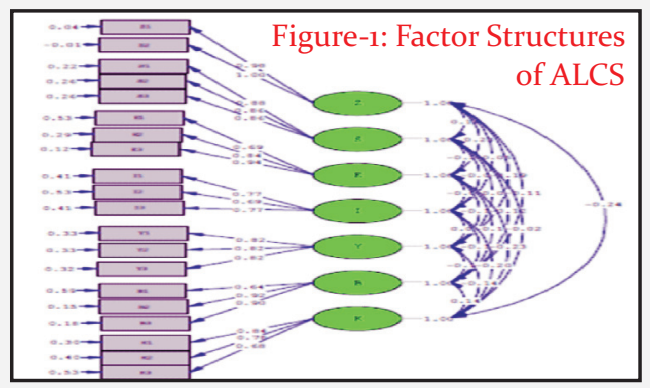


of subscale score of Lack of Time are considered in terms of age groups, MANOVA results show that all the age groups, except for 55-64 age group and 65-74 age group ( $\mathrm{p} \geq 0.05$ ), have a significant correlation between them $(\mathrm{p} \leq \mathrm{0.05})$.

When the distribution of subscale score of Social Effect are considered in terms of age groups, it is determined that all the age groups, except for $45^{-} 54$ and $75^{+}$ age group ( $\mathrm{p} \geq 0.05)$, have a significant correlation ( $\mathrm{p} \leq 0.05)$.

When the distribution of subscale score of Lack of Energy are considered in terms of age groups, it is determined that there is a significant correlation between 65-74 age group and 45-54 age group, and between 55-64 age group and $75^{+}$age group $(\mathrm{p} \leq 0.05)$; however, no significant correlation was found between othergroups .

When the distribution of subscale score of Lack of Will are considered in terms of age groups, it is determined that there is a significant correlation between $45-54$ age group and 55-64 age group and between $65-74$ and $75+$ age group ( $\mathrm{p} \leq \mathrm{0.05}$ ); nevertheless, no significant correlation was found between other groups.

When the distribution of subscale score of Fear of Injury are considered in terms of age groups, it is determined that no significant correlation was found between the subscales.

When the distribution of subscale score of Lack of Skill are considered in terms of age groups, it is determined that there is a significant correlation between 45-54 age group and 55-64 age group and between 65-74 age group and 75+ age group ( $\mathrm{p} \leq 0.05)$; however, no signif icant correlation was found between othergroups.

When the distribution of subscale score of Access to Resources are considered in terms of age groups,it is determined that there is no significant correlation between 55-64 age group and 65-74 age group and between 65-74 age group and $75^{+}$age group $(\mathrm{p} \leq 0.05)$; however, there is a significant correlation between other age groups $(\mathrm{p} \geq 0.05)$.

Table 7: Distribution of scale scores according to gender

\begin{tabular}{lllllllll}
\hline Measure & Female $=2855$ & \multicolumn{2}{l}{ Male=2155 } & & \\
& $\mathrm{M}$ & $\mathrm{SD}$ & $\mathrm{M}$ & $\mathrm{SD}$ & $\mathrm{F}_{(3.5006}$ & $\mathrm{p}$ & $\eta 2$ & Power \\
\hline LT & $\mathbf{2 . 0 0}$ & 0.95 & 2.00 & 0.98 & 0.306 & 0.580 & 0.000 & 0.086 \\
SE & 1.82 & 0.92 & 1.77 & 0.94 & 4.05 & 0.044 & 0.001 & 0.521 \\
LE & 2.05 & 0.81 & 2.07 & 0.78 & 1.26 & 0.261 & 0.000 & 0.202 \\
LW & 1.94 & 0.79 & 2.00 & 0.78 & 6.30 & 0.012 & 0.001 & 0.709 \\
FI & 1.90 & 0.84 & 1.88 & 0.86 & 0.41 & 0.519 & 0.000 & 0.099 \\
LS & 1.77 & 0.90 & 1.83 & 0.87 & 5.34 & 0.021 & 0.001 & 0.637 \\
AR & 1.71 & 0.89 & 1.75 & 0.86 & 2.16 & 0.142 & 0.000 & 0.312 \\
\hline
\end{tabular}

LT-Lack of Time; SE-Social Effect; LE-Lack of Energy; LW-Lack of Will; FI-Fear of Injury; LS-Lack of Skill; Ar-Access of resources

As a result of the data analysis, when the distribution of subscale scores according to gender are examined, there is a significant correlation between gender in the "social effect", "lack of will" and "lack of skill" subscales ( $\mathrm{p} \leq 0.05)$.

When the scale mean score distributions are examined in terms of body mass index groups, the lack of energy mean of the individuals with normal weights
$(\mathrm{M}=2.01 \pm 0.81)$ is found significantly lower than both the overweight $(\mathrm{M}=2.08 \pm 0.79)$ and obese $(\mathrm{M}=2.07 \pm 0.80)$ groups' mean scores. On the other hand, no significant difference was found in other subscales.

Table 8: Distribution of Scale Scores According to Body Mass Index

\begin{tabular}{lllllllllll}
\hline \multicolumn{10}{c}{ Normal (Nor); Over Weight (OWt); Obese } \\
\multicolumn{1}{c}{ Nor=1302 } & OWt-2780 & \multicolumn{2}{l}{ Obese-928 } \\
\hline M & SD & M & SD & M & SD & $F_{(3.5006)}$ & p & $\eta 2$ & Power \\
LT & 1.99 & 0.93 & 2.02 & 0.96 & 1.94 & 1.02 & 2.397 & 0.091 & 0.001 & 0.486 \\
SE & 1.83 & 0.92 & 1.80 & 0.93 & 1.76 & 0.93 & 1.701 & 0.183 & 0.001 & 0.360 \\
LE & 2.01 & 0.81 & 2.08 & 0.79 & 2.07 & 0.80 & 4.037 & 0.018 & 0.002 & 0.722 \\
LW & 1.95 & 0.78 & 1.98 & 0.79 & 1.95 & 0.79 & 1.070 & 0.343 & 0.000 & 0.239 \\
FI & 1.89 & 0.85 & 1.89 & 0.85 & 1.90 & 0.84 & 0.054 & 0.947 & 0.000 & 0.058 \\
LS & 1.78 & 0.91 & 1.80 & 0.89 & 1.82 & 0.85 & 0.775 & 0.461 & 0.000 & 0.183 \\
AR & 1.70 & 0.90 & 1.74 & 0.87 & 1.72 & 0.86 & 0.538 & 0.558 & 0.000 & 0.148
\end{tabular}

LT-Lack of Time; SE-Social Effect; LE-Lack of Energy; LW-Lack of Will; FI-Fear of Injury; LS-Lack of Skıll; Ar-Access of resources

\section{Discussion:}

The literature related to the $\mathrm{f}$ indings of the study which aims to determine the constraints to active life of adults and to compare these in terms of certain demographic variables (gender, age, BMI) is reviewed in this section. According to the study results, the variable "age" has a signif icant main effect on the subscales of Active Life Constraints Scale. When the scores of "lack of time" subscale is considered, it is determined that there is a signif icant correlation between all subscales except for 55-64 age group and 65-74 age group. This situation stems from the fact that $45-54$ age group is in the active work life at that period of their lives; therefore, their scores for "lack of time" is understandably high whereas the scores of 55-64 age group and the other age groups gradually decreases since these adults are generally in either the newly retired population or in the period that covers the later parts of retirement. Gray et al. (2018) conducted a qualitative research on adults who are 50 years of age and above about their perception of exercise constraints. The study revealed that time constraints are a big problem among seniors since they have other businesses to attend to such as taking care of grandchildren. The situation in Turkish population of adults and seniors are indeed similar. It can be observed in daily life that the working class lacks time because of their heavy load of work and the retired population are busy with taking care of their grandchildren. It is also essential to point out that when doing exercise is not habitual, it is hard to make time for physical activities and turn it into a habit. According to Parra et al. (2019), the adults $\mathrm{f}$ ind it difficult to make time for exercise and report time commitment as a constraint. Similarly, "lack of energy" subscale scores also decreased; however, the lowest value was obtained in 65-74 age group. However, the other age groups are mostly among work force; therefore, it is sometimes hard for the working class to $f$ ind energy to do exercise due to their work schedule. 
Also, in the literature, there are qualitative studies with adults who reported fatigue as a constraint (Gray et al., 2018; Vader et al., 2019) which generally causes lack of energy resulting in avoiding exercise. McPhail et al. (2014) also found out in their study with people with musculoskeletal disorders that the participants whose mean age was 53 found it diff icult to do exercise because they lacked the energy to do so. With aging process comes the perceived fatigue. The elderly $f$ inds it diff icult to do what they could do many years ago because they feel tired and their muscles do not function as they used to function.

This is a very common theme in almost every culture. It is also found out that "social effect" and "lack of will" subscale scores decreased as the ages of the participants increased. This might be caused by the fact that the effect of social life decreases with old age and the individuals become more in control of their wills. In the literature, there are many studies suggesting that the physical activity levels of men are higher than women (Ölçücü et al., 2015; Polat \& Simsek, 2015). In the current study, it is determined that there is a significant correlation between genders in the subscales "social effect", "lack of will" and "lack of skill" of Active Life Constraints Scale. These results can be evaluated as gender is a determining factor for constraints that are brought forward in terms of participation in physical activity and maintaining a more active life. Another finding of the current study is that "body mass index" has a signif icant main effect on the subscales of Active Life Constraints Scale. The means of "lack of energy" subscales of the individuals in normal weight group is significantly lower than both overweight and obese participants. In other subscales, no statistically significant difference was found. In the literature, no correlation between the level of physical activity and BMI was found in many studies (Savci et al., 2006; Hallal \& Ark, 2003; Raustrop et al., 2004). Physical activity is important in terms of prevention of weight-gain; however, it is not effective in decreasing body weight alone. Physical activity is only one of the factors that are included in the body weight control programs. In addition to that, physical activity has a health protective effect thanks to metabolic adaptations without a change in the body weight (Raustorp et al., 2004). Therefore, it is natural to $f$ ind studies showing no correlation between the level of physical activity and BMI. However, in the current study, it is determined that the BMIs of the participants put forward "lack of energy" as a constraint to active life. Considering these results, it can be said that as the BMIs of participants increase, their levels of energy that is needed for an active life decrease, and they perceive this situation as a constraint.

As a result, it can be said that according to gender variable, "social effect", "lack of will" and "lack of skill" are the constraints to active life whereas according to body mass index, the most important factor for normal, overweight and obese participants is "lack of energy" as a constraint to active life.

\section{References:}

Camarri, B., Eastwood, P.R., Cecins, N.M., Thompson, P.J. \& Jenkins, S. (2006): Six minute walk distance in healthy subjects aged 55-75years. Respir. Med., 100(4):658-65.

Chou, C.H., Hwang, C.L. \& Wu, Y.T. (2012): Effect of exercise on physical function, daily living activities, and quality of life in the frail older adults: A meta-analysis. Arch. Phys Med. Rehab. 93(2):237-44.

Chodzko-Zajko, W.J., Proctor, D.N., Singh, M.A.F., Minson, C.T., Nigg, C.R., Salem, G.J.\& Skinner, J.S. (2009): Exercise and physical activity for older adults. Med. Sci. Sports Exercise, 41(7):1510-1530.

Demirel, H.,Kayı han, H.,Özmert, N.E.\&Dogan, A. (2014): Physical Activity Guideline of Turkey. (2. Edition). Pub. by:Turkish Health Ministry, Ankara, Turkey.

DiSantis, K.I., Birch, L.L., Davey, A., Serrano, E.L., Zhang, J., Bruton, Y. \& Fisher, J. O. (2013). Physical activity guidelines for adults (19-64 years). Pediatrics, 131(5):e1451-8.

Erbs, S., Hollriegel, R., Linke, A., Beck, E.B., Adams, V., Gielen, S., Mobius-Winkler, S., Sandri, M., Krankel, N., Hambrecht, R. \& Schuler, G. (2010): Exercise Training inPatients With Advanced ChronicHeartFailure(NYHA IIIb)Promotes Restoration of Peripheral Vasomotor Function , Induction of Endogenous Regeneration, and Improvement of Left Ventricular Function. Circulation: Heart Fail., 3(4):486- 494.

Fleg, J.L., Morrell, C.H., Bos, A.G., Brant, L.J., Talbot, L.A., Wright, J.G. \& Lakatta, E.G. (2005): Accelerated longitudinal decline of aerobic capacity in healthy older adults. Circulation, $112(5): 674682$.

Gray, P., Murphy, M., Gallagher, A.\& Simpson, E.E.A. (2018): A qualitative investigation of physical activity compensation among older adults. Br. J. Health Psychol., 23(1):208-224.

Hallal, P.C., Victora, C.G., Wells, J.C.K. \& Lima, R.C. (2003):Physical Inactivity: Prevalence and Associated Variables in Brazilian Adults. Med. Sci. Sports Exercise, 35(11):1894-1900.

Kara, F.M., Gürbüz, B. Sarol, H. (2018):Yetipkinlerde Serbest Zamanda Sýkýlma Algýsý, Algýlanan Sosyal Yetkinlik ve Benlik Saygýsý Düzeyinin Ýncelenmesi.Uluslararasý Spor Egzersiz ve Antrenman Bilimi Dergisi, 4(4):113-121.

Koz, M. (2018). Fiziksel Aktivite ve Rekreasyon Yoluyla Saglýgýn Geliptirilmesi, Uluslararasý Rekreasyon ve Spor Yönetimi Kongresi, 10-13 Mayýs, 2018, Bodrum/Mugla, 10.

Lubans, D., Richards, J., Hillman, C., Faulkner, G., Beauchamp, M., Nilsson, M., Kelly, Paul., Smith, J., Raine, L. \& Biddle, S. (2016): Physical activity for cognitive and mental health in youth: A systematic review of mechanisms. Pediatrics, 138(3):e20161642.

McPhail, S.M., Schippers, M., Marshall, A.L., Waite, M. \& Kuipers, P. (2014): Perceived barriers and facilitators to increasing physical activity among people with musculoskeletal disorders: a qualitative investigation to inform intervention development. Clin. Interven. Aging, 9(1):2113-2122.

Meijer, E.P., Westerterp, K.R. \& Verstappen, F.T.J. (1999):Effect of 


\section{ORIGINAL ARTICLE}

exercise training on total daily physical activity in elderly humans. Eu. J. App. Physiol. Occup. Physiol., 8o(1):16-21.

Ölçücü, B., Vatansever, P., Özcan, G., Çelik, A.\& Paktap, Y. (2015): Üniversite Ögrencilerinde Fi·zi·kse Akti·vi.te Düzeyi. I·le Depresyon ve Anksi·yete I·li·pki·si·. Uluslararasý Türk Egitim Bilimleri Dergisi, 2015(4):294-303.

Parra, D.C.,Wetherell, J.L.,Zandt, A.V., Brownson, R.C., Abhishek, J. \& Lenze, E.J. (2019):A qualitative study of older adults' perspectives on initiating exercise and mindfulness practice. BMC Geriatrics, 19(1):1-11.

Paterson, D.H., Jones, G.R. \& Rice, C.L. (2007): Ageing and physical activity? Evidence to develop exercise recommendations for older adults. Can J. Pub. Health, 98(2):S69-108.

Peeters, P. \& Mets, T. (1996): The 6-Minute Walk as an Appropriate Exercise Test in Elderly Patients With Chronic Heart Failure. L. Gerontol. Biol.Sci. Med.Sci., 5(4):M147-151.

Penedo, F.J. \& Dahn, J.R. (2005): Exercise and well-being: A review of mental and physical health benefits associated with physical activity. Curr. Opin. Psych., 18(2):189-193.

Phelan, E.A., Anderson, L.A., LaCroix, A.Z. \& Larson, E.B. (2004): Older Adults' Views of "Successful Aging" - How Do They Compare with Researchers' Def initions? L. Am. Geriat. Soc., 52(2):211-216.

Polat C. \& Simsek K.Y. (2015): Spor merkezlerindeki bireylerin egzersiz bagýmlýlýgý düzeylerinin incelenmesi: Eskise):hir Ýli Örneði. Akad. Sos. Araptýrmalar Dergisi, 3(15):354-369.

Raustorp, A., Pangrazi, R.P. \& Ståhle, A. (2004): Physical activity level and body mass index among schoolchildren in southeastern Sweden. Acta Paediat., 93(3):400404.

Rejeski, W.J., Focht, B.C., Messier, S.P., Morgan, T., Pahor, M. \& Penninx, B. (2002): Obese, older adults with knee osteoarthritis: Weight loss, exercise, and quality of life. Health Psychol., 21(5):419-426.
Ambient Science, 2020: Vol. 07(Sp1); 07-13 DOI:10.21276/ambi.2020.07.sp1.oa01

Rütten, A. \& Abu-Omar, K. (2004):Prevalence of physical activity in the European Union. Soz. Präventiv Med., 49(1):281-289.

Savcý, S., Öztürk, M., Arýkan, H., Ýnce D.\& Ýnal, T.L. (2006): Üniversite ögrencilerinin $\mathrm{f}$ iziksel aktivite düzeyleri. Türk Kardiyol. Dern. Ars., 34(3):166-172.

Lear, S.A., Hu, W., Rangarajan, S., Gasevic, D., Leong, D.,Iqbal, R., Casanova, A., Swaminathan, S., Anjana, R.M., Kumar, R., Rosengren, A., Wei, L., Yang, W. \& Yusuf, S. (2016): The effect of overall and types of physical activity on mortality and cardiovascular events in 17 countries: Results from the prospective urban rural epidemiologic (Pure) study. Global Heart, $11(2):$ e1.

Schembre, S.M., Durand, C.P., Blissmer, B.J. \& Greene, G.W. (2015):Development and validation of the cognitive behavioral physical activity questionnaire. Am. J. Health Prom., 30(1):58-65.

Soyuer, F., Senol, V. \& Elmali, F. (2012):Huzurevinde Kalan 65 Ya S ve Üstündeki Bireylerin , Fiziksel Aktivite, Denge ve Mobilite Fonksiyonlarý. Van Tip Dergisi, 19(3):116-121.

Spartano,N.L.,Lyass, A.,Larson, M.G., Tran,T., Andersson, C., Blease, S.J., Esliger, D.W., Vasan, R.S. \& Murabito, J.M. (2019): Objective physical activity and physical performance in middle-aged and older adults. Exper. Gerontol., 199(1):203-211.

Vader, K., Doulas, T., Patel, R., \& Miller, J. (2019): Experiences, barriers, and facilitators to participating in physical activity and exercise in adults living with chronic pain: a qualitative study. Disabil. Rehabil., 1-9.

Watson, K.B., Carlson, S.A., Gunn, J.P., Galuska, D.A., O'Connor, A., Greenlund, K.J. \& Fulton, J.E. (2016): Physical inactivity among adults aged 50 years and older United States, 2014. Morbid. Mortal. Week. Rep., 65(36):954-958. 